\title{
Flood damage assessment in agricultural area in Selangor river basin
}

\begin{abstract}
Flooding is the major natural hazard that occurs in Malaysia. Flooding causes loss of lives, injuries, property damage and leave economic damage to the country, especially when it occurs in an agricultural area. There is still a lack of information available on floodplain especially on the impact of flooding in the agricultural area. This study focused on flooding and flooding impact in oil palm plantations, fruits and vegetables area. A river modeling is required to study the impact of flooding and to mitigate the floods using one mitigation option. A flood model was developed using InfoWorks Integrated Catchment Model (ICM) to carry out the analysis for flood damage assessment. With the aim of creating a flood damage map, Geographical Information System (GIS) was combined with the flood model to provide an ideal tool for the analysis of the flood damage and the effect of mitigation to flood damage. The estimated total damage for three different flood event; 10 ARI, 50 ARI and 100 ARI involved millions of ringgits. In order to reduce the flood impact along the Selangor River, a flood mitigation structure which is a retention pond was suggested, modeled and simulated. The effects of the retention ponds were analyzed and evaluated for 10 ARI, 50 ARI and 100 ARI. With this retention pond, flood extents of the flood events in agricultural area were shown capable of reduction significantly by $65.57 \%$ for 10 ARI, $76.18 \%$ for 50 ARI and $72.51 \%$ for 100 ARI.
\end{abstract}

Keyword: Flood model; Agricultural flood damage; Flood mitigation 